\section{Compression of median nerve at elbow}

Compression of the median nerve at the wrist causing carpal tunnel syndrome is an entrapment neuropathy known to every final year medical student. What is not so well known, however, is that compression of the median nerve may occur in the region of the elbow and simulate the clinical features of carpal tunnel syndrome.

\section{Case report}

A 46-year-old man was admitted to St Helier Hospital, Carshalton, for treatment of primary hypercholesterolaemia. He was observed to have considerable wasting of the muscles of the left thenar eminence and probable wasting of the left forearm. On direct questioning he admitted that he had had some weakness of the left hand for several years but denied sensory symptoms. Neurological examination showed gross weakness of the left thumb with wasting of abductor pollicis brevis, flexor pollicis brevis, and possibly flexor carpi radialis. Perception of sharp and blunt in the pulp of the left index finger was diminished, but sensation in the hand was otherwise normal. There were no localised areas of tenderness in the arm or hand. Investigations included normal radiographs of the chest, elbows, and cervical spine. No supracondylar spurs were present. Electromyography suggested compression of the median nerve at the level of the elbow and it was decided to explore this region.

With a tourniquet on the upper arm a 10-cm Z-shaped incision was made over the anterior aspect of the elbow and the bicipital aponeurosis divided. The median nerve was identified and traced along its course. A shiny white ligamentous band $3 \mathrm{~mm}$ in diameter was found lying parallel with, but separate from, the upper border of pronator teres and passing from the medial epicondyle of the humerus to just below the tuberosity of the radius. This band passed across both the median nerve and the brachial artery and tightly constricted the nerve (see figure). The band was divided and excised to release the nerve. Histological examination of the band showed normal ligamentous tissue.

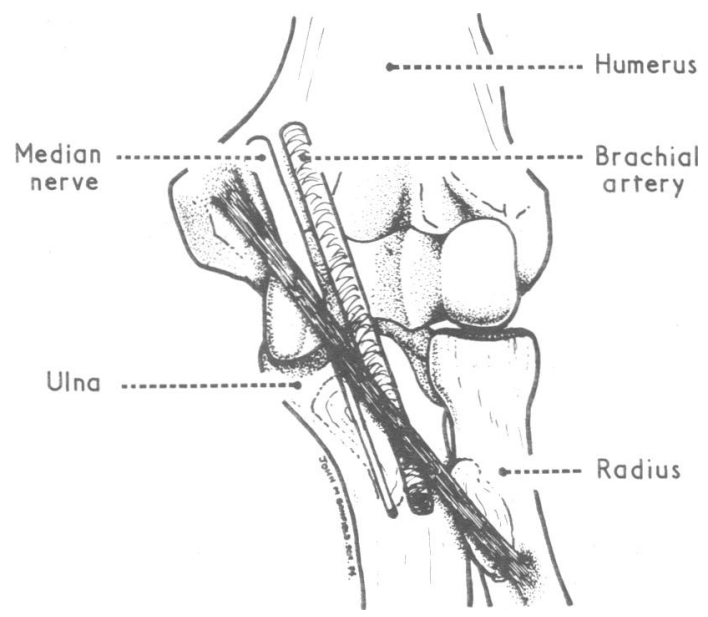

Diagram showing ligament passing across elbow joint from medial epicondyle to radius and constricting median nerve.

\section{Discussion}

The pronator syndrome is calised by the entrapment of the main trunk of the median nerve in the region of the two heads of pronator teres before it dips beneath the tendinous bridge of flexor digitorum sublimis. ${ }^{1}$ It may easily be misdiagnosed as carpal tunnel syndrome or thought to be caused by cervical spondylitis; occasionally it has been mistaken for a toxic neuritis. The sensory impairment may be identical to that in carpal tunnel syndrome, but weakness of the long and short flexor muscles of the fingers often predominates as the median nerve supplies the lateral part of flexor digitorum profundus and the whole of flexor digitorum sublimis. Tenderness over the pronator teres at the site of entrapment is sometimes a diagnostic pointer. Classically, the compression is caused by hypertrophy of the pronator teres muscle itself or by a tendinous band within the ulnar head of pronator teres. Rarely, the tendinous bridge of flexor digitorum sublimis may be the cause. There may, however, be considerable variation in the amount of fibrous tissue associated with the two heads of both flexor digitorum sublimis and pronator teres, as well as variation in the origin of pronator teres. ${ }^{2}$ Although we can find no published record of the ligament we describe in this paper, it seems unlikely that it is a unique case, and we believe the diagnosis in our patient was that of pronator syndrome.

The main trunk of the median nerve may also be compressed by the supracondylar ligament of Struthers, which lies above the hinge of the elbow joint and passes from a spur on the anteromedial aspect of the humeral shaft to the medial epicondyle. ${ }^{3}$ Rarely, the anterior interosseous branch of the median nerve may be separately compressed by a fibrous band of variable origin and insertion associated with either flexor digitorum sublimis or pronator teres, causing weakness of the thumb and index finger."

We thank Mr A York Mason for permission to make this report; Dr D Kendall, of St Helier Hospital, and Dr D A H Yates, of St Thomas's Hospital, London, for their help in diagnosis; Dr G H Wright, lecturer in anatomy in the University of Cambridge, for his interest; and $\mathrm{Mr} \mathrm{J}$ Banfield for the illustration.

${ }^{1}$ Kopell, H P, and Thompson, A L, New England fournal of Medicine, 1958, 259, 713.

${ }^{2}$ Fearn, C B D'A, and Goodfellow, J W, fournal of Bone and foint Surgery, 1965, 47B, 91 .

${ }^{3}$ Kessel, L, and Rang, M, Fournal of Bone and foint Surgery, 1964, 48B, 765.

4 Farber, J S, and Bryan, R S, Fournal of Bone and foint Surgery, 1968, 50A, 521 .

St Helier Hospital, Carshalton, Surrey

M J KELLY, FRCS, MRCP, senior house officer (now surgical registrar, Addenbrooke's Hospital, Cambridge)

B T JACKSON, MS, FRCS, senior surgical registrar (now consultant surgeon, St Thomas's Hospital, London)

\section{Severe hypertension produced by interaction of phenylpropanolamine with methyldopa and oxprenolol}

The sympathomimetic amine phenylpropanolamine, which is present in many proprietary "cold cures," antagonises the hypotensive effect of bethanidine and guanethidine and causes hypertension in patients on monoamine oxidase inhibitors. ${ }^{1}$ I would like to report a severe hypertensive reaction to this drug in a patient with renal hypertension treated with methyldopa and oxprenolol.

\section{Case report}

The patient was a 31-year-old mining engineer. After an attack of acute glomerulonephritis in 1958, when he was 14 , his urine was noted to contain red cells, albumin, and casts on several occasions. He remained well, however until May 1975, when he went to his general practitioner complaining of headaches and was found to have a blood pressure of $200 / 120 \mathrm{~mm} \mathrm{Hg}$ and a blood urea level of $22 \mathrm{mmol} / 1$ (133 mg/100 ml.) His iypertension was easily controlled on methyldopa $250 \mathrm{mg}$ twice daily and oxprenolol $160 \mathrm{mg}$ three times a day with repeated clinic readings of $140 / 80 \mathrm{~mm} \mathrm{Hg}$, but his renal function continued to deteriorate and by September 1975 his blood urea level was $30.4 \mathrm{mmol} / 1(183 \mathrm{mg} / 100 \mathrm{ml})$. On 15 December 1975 he visited his general practitioner, who recorded his blood pressure as 120 / $70 \mathrm{~mm} \mathrm{Hg}$ and prescribed Triogesic tablets (phenypropanolamine $12.5 \mathrm{mg}$ and paracetamol $500 \mathrm{mg}$ ) in a dose of two tablets three times a day as symptomatic treatment for a cold. When seen at the clinic two days later the patient complained of decreasing energy, occasional headaches, and increasing nausea over the preceding few weeks and paraesthesiae in his hands and feet since the onset of his cold. In addition to the Triogesic he had continued on his normal antihypertensive treatment. At this time his blood pressure was $200 / 150 \mathrm{~mm} \mathrm{Hg}$ and pulse rate 90 beats $/ \mathrm{min}$. There were no objective signs of peripheral neuropathy, no hypertensive retinopathy, and no signs of heart failure. His blood urea level had risen to $42 \mathrm{mmol} / 1$ ( $253 \mathrm{mg}$ / $100 \mathrm{ml}$ ). The Triogesic was stopped but he continued on his usual doses of methyldopa and oxprenolol, and by the next day his blood pressure was $140 / 110 \mathrm{~mm} \mathrm{Hg}$ and his paraesthesiae had disappeared. He continued to vomit, however, and was therefore started on peritoneal dialysis the next 